\title{
Water profiles in vertical slot fishways without central baffle
}

\author{
Guangning Li*, Shuangke Sun, Haitao Liu, Tiegang Zheng, Chao Zhang \\ Key Laboratory of Simulation and Regulation of Water Cycle in River Basin, China, Institute of \\ Water Resources and Hydropower Research, Beijing 100038, China
}

Email:1gnchina@163.com

\begin{abstract}
This paper examines the water depth variations of vertical slot fishways (VSFs) without central baffle. Three experimental models are built for the research. The results show that: the adjoining pools should have the same fore-and-aft elevation difference to prevent obvious fluctuation of water depth. Instead of being uniform along the fishway, the water depth is affected by upstream and downstream water levels. The fluctuations of the water levels exert an impact to over a dozen pools at the end of the fishway. The water line characteristics are different when the downstream water depth is greater or smaller than the normal conditions. Under the working condition of backwater, the water depth increases uniformly in pools in the backwater section; under the condition of drawdown, the depth falls faster in the pools closer to the end of the fishway. Two flow profiles are obtained from the VFS: the M1 and M2, which are analyzed by the Bakhmeteff-Chow method. These findings help enhance the understanding of the hydraulic design of the fishway, and improve efficiency of the VSFs.
\end{abstract}

Keywords: Water depth, Vertical slot fishways, Experimental models, Central baffle.

\section{INTRODUCTION}

Featuring stable flow pattern and favorable effect on fish migration, vertical slot fishways (VSFs) has been more extensively applied across the world than any other fishway. Each VSF has an open channel with a sloping bottom, which is divided into a number of pools by vertically slotted crosswalls. With this configuration, the total height of the obstacle is separated into small water head drops and jet flows are created at the slots. The amount of energy contained in the jet is dissipated in pools by jet mixing.

The characteristics of the open channel, ranging from the variation in bottom slope and roughness along the channel, the cross-sectional geometry to the size of the channel, have a direct impact to the hydraulic elements of the fishway, e.g. water depth and velocity and the form of surface water line, which in turn influences the design and project cost of the fishway. Therefore, the economy and stability of the fishway hinges on the reasonable design of water line.

Out of the many scholars probing into the water structures of pools [1,2], only a few have examined the water depths in the VSFs. Rajaratnam et al.[3] conduct an experimental study on the hydraulics of VSFs, and obtain conceptual backwater profile (M1) and drawdown profile (M2) (plus an approximate uniform flow profile) under different tail water scenarios. It is concluded that the dead drop is the same across the pools if the flow profile is uniform, and the inverse is true. The M1 and M2 under non-uniform flow are analyzed by Bakhmeteff-Chow [4] method. J. F. Fuentes-Pérez et al. [5] simulate the performance of VSFs under uniform and nonuniform flows using discharge coefficients involving the downstream water level by a logical algorithm.

Nevertheless, the previous research only studies relatively short VSFs with several geometrically identical pools (length, wide $\& \Delta \mathrm{Z}$ ). Few data are available on the water depth in a relatively long fishway with dozens of pools. The water depth variation pattern may differ to some extent if the pools take different shapes, such as rest pool, turning pool, etc. Besides, the numbers of pools simulated in experiments are far fewer than that of the VSF in reality, making it necessary to take more pools into account to disclose water depth variation law. There is also the lack of systematic study on the variation in water depths due to the fluctuations of upstream and downstream water levels because the fluctuations pose a huge challenge to fishway design.

Similar to the Hell's Gate on the Fraser River in British Columbia, most VSFs have a central baffle on the baffle plate. However, a series studies in China prove that the central baffle only has a minor effect on flow pattern variation $[6,7]$. Thanks to the extensive numerical investigations on the position and size of central baffle, it is found that the effect of the central baffle is minimal and limited around the end of cross walls. Thus, it is possible to remove the central baffle from the design. The removal also helps prevent deposition of debris or sediments 
Against this backdrop, the author carries out three VSFs experiments based on the law of gravity similarity and studies the water depth in the pools. The research is targeted at: (1) introducing a VSF structure without central baffle; (2) disclosing the water depth variation pattern in relatively long VSFs with dozens of pools; (3) looking for the shared water depth variation pattern in VSFs without central baffle.

\section{EXPERIMENT DESIGN}

\subsection{The proposed VSFs structure without central baffle}

The proposed VSFs structure is shown in Figure 1. Zhang et al. [8] suggest that the flow structure of such fishways depends on the aspect ratio of pools, the length and deflecting angle of baffle plate, and slot width.

The parameters of the VSFs are recommended as follows: $\mathrm{b} / \mathrm{B}=0.15 \sim 0.20, \mathrm{P} / \mathrm{B}=0.20 \sim 0.34$ (length of baffle plate), $\theta$ $=45^{\circ}$ (angle of baffle plate), $\mathrm{L} / \mathrm{B}=8: 8 \sim 10.5: 8$ (length/width ratio). Following the example of the Hell's Gate, the water slope is $1: 3$ in the front and 1:1 in the back for partition pier walls, and the slope is $1: 1$ inthe front and 1:3 in the back for guide walls. This structure has been successfully applied by Sun Shuangke [6] to the fishway of Shangzhuang Gate.

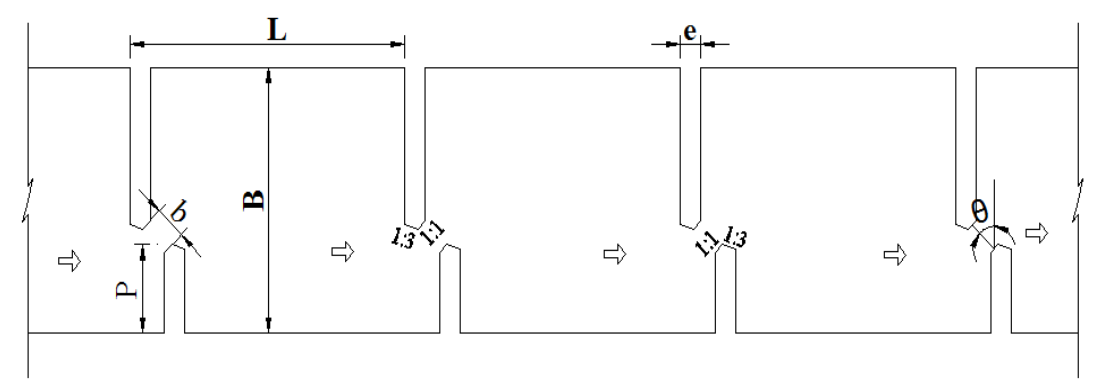

Figure 1. Sketch of vertical slot fishway without central baffles. L, the length of the pool; B, the width of the pool; $b$, the width of the slot; P, the length of the baffle plate; e, the thickness of the baffle plate; $\theta$, the deflecting angle of the baffle plate

\subsection{Three models}

Located in southwestern China, the three VSFs without central baffle are modeled by the law of gravity similarity. All of them have dozens of pools. (Figure 2)

The first VSF (Zhentouba Dam) involves 61 slots, two $90^{\circ}$ turns and several rest pools. The average slot width $\mathrm{b}=0.3 \mathrm{~m}$, the average pool width $\mathrm{B}=2.0 \mathrm{~m}(\mathrm{~b} / \mathrm{B}=0.15)$, the average pool length $\mathrm{L}=2.5 \mathrm{~m}(\mathrm{~L} / \mathrm{B}=10: 8)$, the cross-wall thickness e $=0.2 \mathrm{~m}$, and the average $\Delta \mathrm{Z}=0.083 \mathrm{~m}$. Hence, the average slope of the VSF $S=\Delta Z /(L+e)=3.0 \%$. The lateral baffle length $\mathrm{P}=0.5 \mathrm{~m}$.

The second VSF (Duobu Dam) involves 70 slots, two $90^{\circ}$ turns, one $180^{\circ}$ turn and several rest pools. All of the pools share the same $\Delta \mathrm{Z}$. The average slot width $\mathrm{b}=0.3 \mathrm{~m}$, the average pool width $\mathrm{B}=2.0 \mathrm{~m}(\mathrm{~b} / \mathrm{B}=0.15)$, the average pool length $\mathrm{L}=2.5 \mathrm{~m}(\mathrm{~L} / \mathrm{B}=10: 8)$, the cross-wall thickness $\mathrm{e}=0.2$ $\mathrm{m}$, and the average $\Delta \mathrm{Z}=0.0575 \mathrm{~m}$. Hence, the average slope of the VSF $S=\Delta Z /(L+e)=2.3 \%$. The lateral baffle length $\mathrm{P}=0.5 \mathrm{~m}$.

The third VSF (Anggu Dam) involves 81 slots and two $180^{\circ}$ turn. The average slot width is $\mathrm{b}=0.4 \mathrm{~m}$, the average pool width $\mathrm{B}=2.5 \mathrm{~m}(\mathrm{~b} / \mathrm{B}=0.16)$, the average pool length $\mathrm{L}=$ $3.2 \mathrm{~m}(\mathrm{~L} / \mathrm{B}=10.24: 8)$, the thickness of the cross-wall $\mathrm{e}=$ $0.25 \mathrm{~m}$, the mean $\Delta \mathrm{H}=0.048 \mathrm{~m}$. Hence, the average slope of the VSF $\mathrm{S}=\Delta \mathrm{Z} /(\mathrm{L}+\mathrm{e})=1.5 \%$. The lateral baffle length $\mathrm{P}=0.625 \mathrm{~m}$.
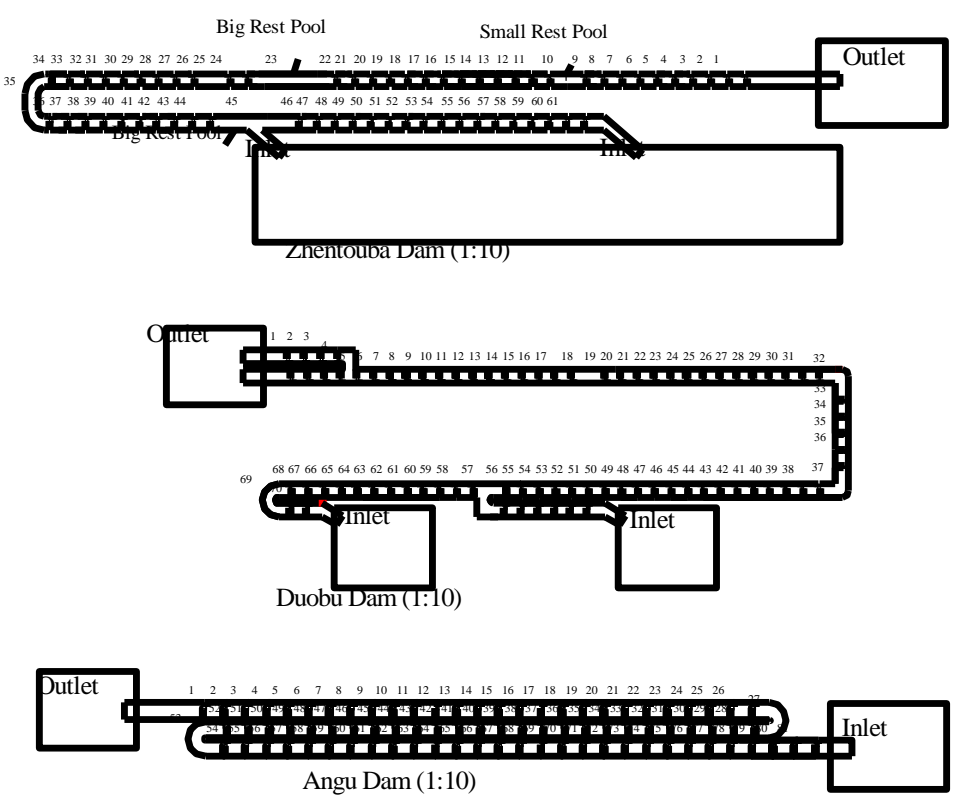

Figure 2. The layout of three vertical slot fishway experiments 


\subsection{Measurement of water depths}

During the experiment, the flow rate is controlled by the water tanks and the gates located in the upstream of the structures and are measured by electromagnetic flowmeter. To simulate different hydrodynamic scenarios, the gates are manipulated to adjust the water depth and discharge through the fishways.

In the same pool, the water surface is roughly at the same elevation. The phenomenon is attributable to the small overcurrent flow quantity of the fishway, the small average flow velocity in different sections of each pool, and the near-zero water surface slope in each pool. In light of the above, the author conducts a test on the pools. Measured by a graduated scale, water depth at the central section represents that of each pool. Successive measurements are made to obtain a stable average value.

\section{RESULTS}

All the three tests are designed based on the law of gravity similarity and measured according to the same standard. The test procedures are repeated to record and analyze the water depths, aiming at disclosing the water depth variation pattern. The main scenarios are listed in Table 1, and all the upstream and downstream water depths are in the prototype.

Table 1. Operating scenarios for experiments

\begin{tabular}{c|c|c|c|c|c|c}
\hline \multirow{4}{*}{ Scenarios } & \multicolumn{2}{|c|}{ Zhentouba Dam } & \multicolumn{2}{c}{ Duobu Dam } & \multicolumn{2}{c}{ Angu Dam } \\
\cline { 2 - 7 } & $\begin{array}{c}\text { Upstream } \\
\text { water depth } \\
(\mathrm{m})\end{array}$ & $\begin{array}{c}\text { Downstream } \\
\text { water } \\
\text { depth } \\
(\mathrm{m})\end{array}$ & $\begin{array}{c}\text { Upstream } \\
\text { Water } \\
\text { Depth } \\
(\mathrm{m})\end{array}$ & $\begin{array}{c}\text { Downstream } \\
\text { Water } \\
\text { depth } \\
(\mathrm{m})\end{array}$ & $\begin{array}{c}\text { Upstream } \\
\text { water depth } \\
(\mathrm{m})\end{array}$ & $\begin{array}{c}\text { Downstream } \\
\text { water } \\
\text { depth } \\
(\mathrm{m})\end{array}$ \\
\hline 1 & 1.03 & 2.03 & 2.49 & 1.53 & 1.30 & 1.51 \\
\hline 2 & 1.35 & 1.61 & 1.48 & 2.44 & 1.70 & 1.70 \\
\hline 3 & 1.35 & 0.75 & 2.57 & 2.45 & 1.70 & 1.08 \\
\hline 5 & 1.35 & 1.02 & 1.81 & 1.12 & & 0.72 \\
\hline 6 & 1.35 & 1.35 & 1.83 & 1.42 & & \\
\hline
\end{tabular}

\subsection{VSF model of the Zhentouba Dam}

The tests are conducted under different scenarios. When the water is the same deep in the upstream and downstream (Scenario 5), the water depth remains roughly the same in pools 1\# 10\#, 45\# and 61\# $(1.35 \mathrm{~m})$, and fluctuates significantly in pools $10 \# \sim 45 \#$; the difference between the maximum and the minimum water depths is $0.5 \mathrm{~m}$ in the prototype (Figure 3 ).
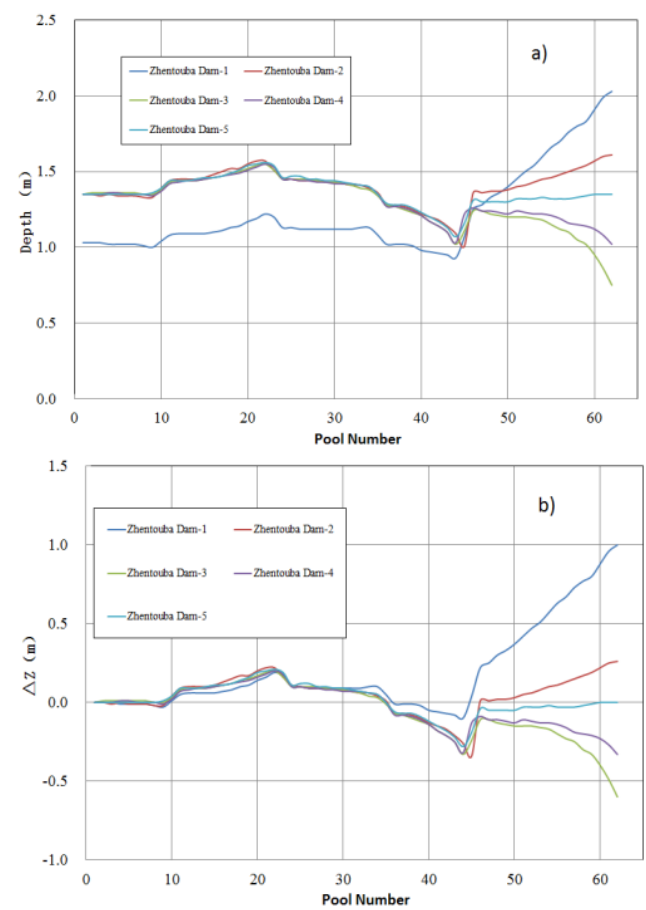

Figure 3. Typical water depth and $\Delta \mathrm{Z}$ plots of Zhentouba Dam VSF
Analysis shows that the difference is the result of the improper slope design of small rest pool, large rest pool, turning pool and the inlet section of pool 1\#. In this model, the small rest pool (10\# pool) is twice as long as a normal pool, but the bottom slope is still 3\%. Thus, the fore-and-aft elevation difference in the $10 \#$ pool is $0.15 \mathrm{~m}$, twice that of a normal pool $(2.5 \times 3 \%=0.075 \mathrm{~m})$. The large rest pool $(23 \#$ pool) is four times longer than a normal pool, but has a bottom with no slope. The turning pool (35\# pool) also has a bottom with no slope. The fore-and-aft elevation difference of the 1 \# fishway inlet section (45\# pool) (length: 5 times that of a normal pool; bottom slope: $3 \%$ ) is $0.375 \mathrm{~m}$. Due to the different bottom slopes, two flow patterns are exhibited by the water line distribution: backwater profile (10\# 23\#) and drawdown profile (23\# 45\#).

Therefore, it is recommended to impose strict control on the bottom slope of important sections during the hydraulic design of fishways. The important sections include small rest pool, large rest pool, turning pool and inlet section. The foreand-aft elevation difference in these sections should be the same with the normal pools. In this fishway, it should be $\Delta \mathrm{Z}=$ $0.075 \mathrm{~m}$ to allow the bottom slope to adapt to the pool length.

\subsection{VSF model of the Duobu Dam}

The bottom slope is strictly controlled in the VSF model of the Duobu Dam. The fore-and-aft elevation difference of turning pools equals that of a normal pool: $\Delta \mathrm{z}=0.0575 \mathrm{~m}$, allowing the bottom slope to adapt to the pool length.

When the water is almost the same deep in the upstream and downstream (Scenario 3), there is no sharp fluctuation in water depth (Figure 4). This means all the small rest pools, turning pools and inlet sections act as normal pools, an evidence to the effectiveness of the design.

Whether the water is deeper in the upstream or in the downstream, the water depth variation always occurs in the second half of the fish way (pools 35\# and 70\#). For the first 
half of the fishway (pools $1 \# \sim 35 \#$ ), there is no obvious change to water depth.

From pools $35 \# \sim 70 \#$, the water depth varies in different degrees. Relatively speaking, the variation gradient is steeper in pools 50\# 70\#. Thus, water depth variation mainly appears in over a dozen pools near the end of the fishway.

When the water is deeper in the upstream or in the downstream, backwater profile (M1) or drawdown profile (M2) are formed in the VSF, especially at the last 20 pools. For M1, the water depth increases roughly uniformly. For M2, the water depth does not increase in a uniform manner. Instead, the depth falls faster in the pools closer to the end of the fishway.
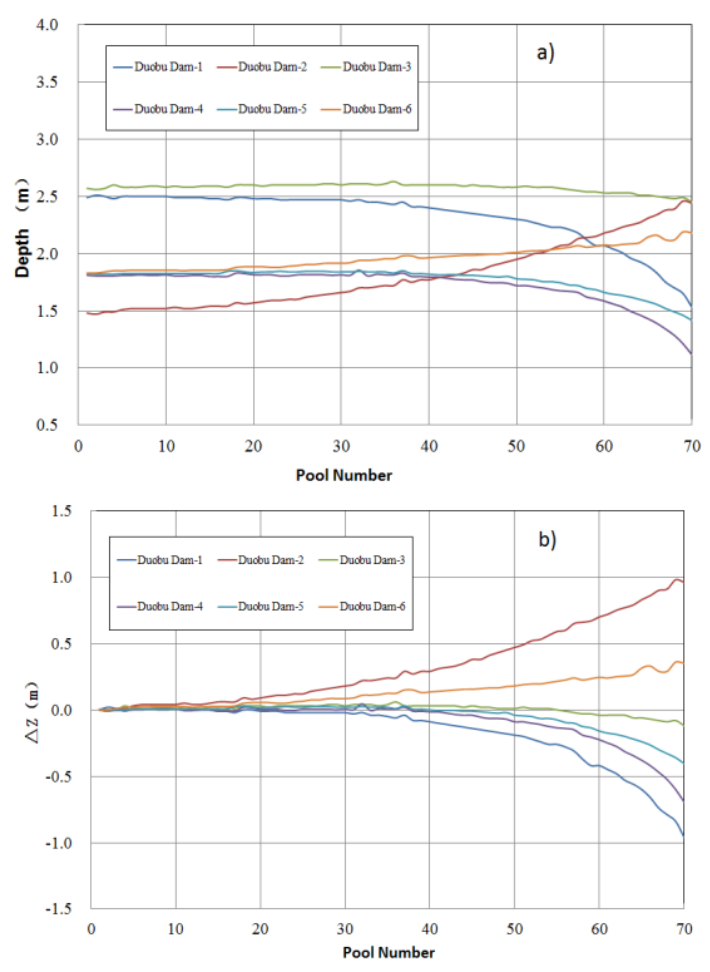

Figure 4. Typical water depth and $\Delta \mathrm{Z}$ plots of Duobu Dam VSF

\subsection{VSF model of the Anggu Dam}

The bottom slope is also strictly controlled in the VSF model of the Anggu Dam. In the important sections, including small rest pool, turning pool and inlet section, the fore-and-aft elevation difference is kept equal to that of normal pools, $\Delta \mathrm{Z}$ $=0.048 \mathrm{~m}$.

Whether the water is deeper in the upstream or in the downstream, the water depth variation always occurs in the second half of the fish way (pools 40\# and 81\#). For the first half of the fishway (pools 1\# 40\#), there is no obvious change to water depth (Figure 5).

From pools $40 \# \sim 81 \#$, the water depth varies in different degrees. Relatively speaking, the variation gradient is steeper in pools $70 \# \sim 81 \#$ than that in pools $41 \# \sim 70 \#$. Thus, water depth variation mainly appears in the last 10 pools at the end of the fishway.

When the water depth remains at a fixed depth in the upstream and changes in the downstream, the water depth variation mainly happens in the last 10 pools at the end of the fishway. The water line characteristics are different when the downstream water depth is greater or smaller than the uniform conditions. For M1, the water depth increases uniformly in pools in the backwater section. For M2, the depth falls faster in the pools closer to the end of the fishway.
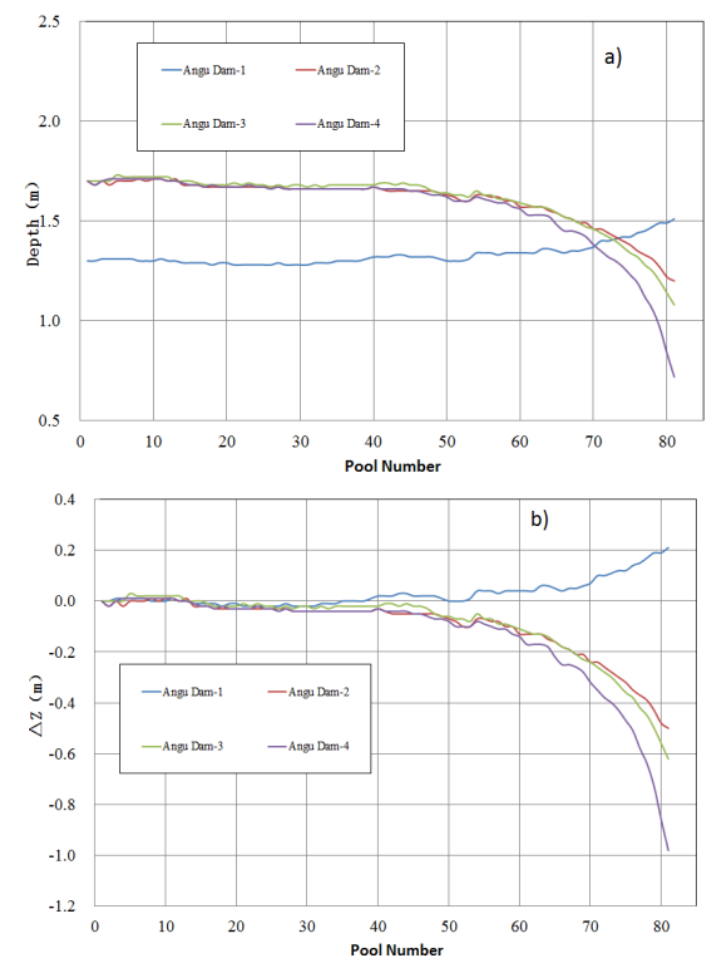

Figure 5. Typical water depth and $\Delta \mathrm{Z}$ plots of Angu Dam VSF

\section{DISCUSSION}

The water line in the VSF is associated with many factors, such as bottom slope, roughness, and form drag. The experiments reveal that the longitudinal slope in each pool is key to the water depths in the VSF. By adjusting the bottom slope of the pools, it is found that the adjoining pools should have the same fore-and-aft elevation difference $(\Delta \mathrm{Z})$ to prevent obvious fluctuation of water depth. In other words, the small rest pool, large rest pool, turning pool and inlet section ought to share the same $\Delta \mathrm{Z}$ in a VSF. Given the relationship between $\mathrm{S}$ and $\Delta \mathrm{Z}$, different slopes should be used in specific pools. This is a feasible way to prevent obvious variation in water depth.

The experiment results demonstrate that: instead of being uniform along the fishway, the water depth is affected by upstream and downstream water levels. Thus, the author alters the downstream water level and measures the corresponding water depths. It is discovered that M1 appears when the downstream water level is increased, and M2 appears when the level is decreased. If the water level is higher in the downstream, the water depth in each of the pools in the backwater section will rise uniformly by almost the same margin; if the water level is lower in the downstream, the water depth will decrease and the gradient will be dependent on the slope and elevation difference [9].

The results on M1 and M2 are plotted with the $\mathrm{y} / \mathrm{y}_{0}$ and the pool number (Figure 6). As shown in the figure, the pools are numbered from the downstream of the section, the (vertical) depth $\mathrm{y}$ is $1.05 \mathrm{y}_{0}$ for $\mathrm{Ml}$ curves and $0.95 \mathrm{y}_{0}$ for M2 curves. The $\mathrm{y}_{0}$ is normal (or uniform) flow depth. According to the figure, the results of the VSFs are well illustrated one curve for $\mathrm{M}$ l and another for M2. 


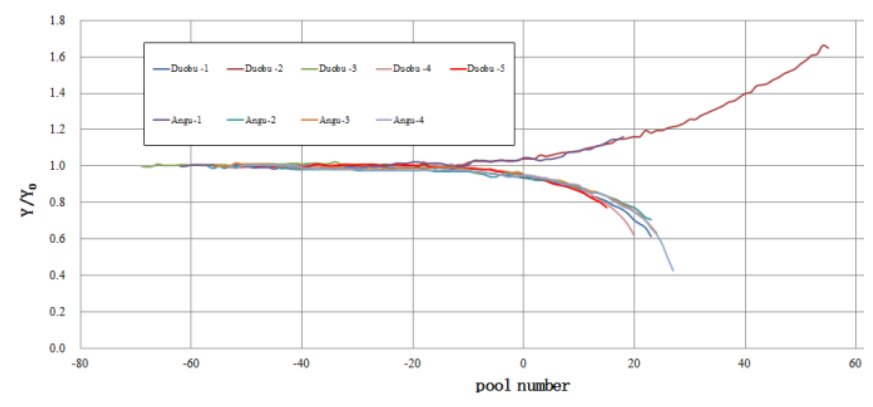

Figure 6. The dimensionless water profiles

For a given water depth $\mathrm{y}_{\mathrm{n}}$, the distance of the fishway from the section $\left(\mathrm{x}_{\mathrm{n}}\right)$ is analyzed as follows: Assume that all the pools are the same (all have the same $\Delta \mathrm{Z}$ and $\mathrm{L}$ ), and the distance from the section $\mathrm{X}=\mathrm{PN} \mathrm{N}^{*} \mathrm{~L}$; map the figure to a coordinate system of $\mathrm{y} / \mathrm{y}_{0}$ and $\mathrm{x} / \mathrm{L}_{0} ;$ Obtain the $\mathrm{XL}$ corresponding to the given yn by the method proposed by Rajaratnam et al. [3], and get the number of a pool $\mathrm{PNn}=$ $\mathrm{X}_{\mathrm{L}} / \mathrm{L}$. According to the Bakhmeteff-Chow method [4], the following equation can be obtained.

$\mathrm{X}=\left(\mathrm{y}_{0} / \mathrm{s}_{0}\right) * \mathrm{G}\left(\eta, \mathrm{N}, \mathrm{M}, \mathrm{F}_{0}\right)$

where $\mathrm{X}=\mathrm{PN} * \mathrm{~L}$ is the longitudinal distance along the bottom (from the origin); $\mathrm{y}_{0}$ is the normal (or uniform) flow depth; $\mathrm{s}_{0}$ is the bed slope; $G$ is the Bakmeteff-Chow varied-flow function; $\eta$ is equal to $y / y_{0}$ with $y$ being the depth at any $x ; N$ and $M$ are indexes for uniform and critical flows, respectively; $\mathrm{F}_{0}$ is the Froude number of uniform flow.

Then, calculate the reality $\mathrm{x}_{\mathrm{n}}$ by adding up the lengths of the $\mathrm{n}$ pools $\mathrm{x}_{\mathrm{n}}=\mathrm{PN} 1 * \mathrm{~L} 1+\mathrm{PN} 2 * \mathrm{~L} 2+\mathrm{PN} 3 * \mathrm{~L} 3 \ldots \mathrm{PNn} * \mathrm{Ln}$. The water surface curves of the VSFs can be obtained based on Figure 6 and this formula.

In reality, it is very difficult to keep the water level constant at the upstream and the downstream [10, 11]. If the water is deeper in the downstream, the flow rate in the slots will fall below the designed burst speed, and the fish movement in the upstream will not be affected. If the water is deeper in the upstream, the flow rate in the slots will increase dramatically due to the falling water level of the pools at the end of the fishway. In several pools, the upstream movement of the fish will be impeded. The following measures should be taken to resolve the problem: 1) provide more inlets to reduce water depth variation gradient in each inlet across all scenarios; 2) control the flow rate under a reasonable value by widening the vertical slots in several pools at the end of the fishway

\section{CONCLUSION}

This paper introduces a new structure of VSF without central baffle. Based on the law of gravity similarity, three VSFs without central baffle are designed for experiments, in which the water surface curves are measured by a graduated scale. The water line in the VSF is associated with many factors, such as bottom slope, roughness, and form drag. It is proved that the fore-and-aft elevation difference in critical sections like small rest pool, large rest pool, turning pool and inlet section should be kept equal to that of the normal pools. Besides, all the small rest pools, turning pools and inlet sections act as normal pools. In order to maintain water depth, the $\Delta \mathrm{Z}$ of the fore-and-aft in the adjoining pools should be same. Instead of being uniform along the fishway, the water depth is affected by upstream and downstream water levels. The fluctuations of the water levels exert an impact to over a dozen pools at the end of the fishway. The water line characteristics are different when the downstream water depth is greater or smaller than the normal conditions. The results on M1 and M2 are plotted with the $\mathrm{y} / \mathrm{y} 0$ and the pool number, which are analyzed by the Bakhmeteff-Chow method. The water level variation mainly affects over a dozen pools at the end of the fishway, and the velocity in the slots increases dramatically due to the plunge of water level in these pools.

\section{ACKNOWLEDGMENT}

This research was supported by the National Natural Science Foundation of China (No.51679261).

\section{REFERENCES}

[1] Wu S., Rajaratnam N., Katopodis C. (1999). Structure of flow in vertical slot fishway, J. Hydraul. Eng., Vol. 125, No. 4, pp. 351-360.

[2] Liu M., Rajaratnam N., Zhu, D.Z. (2006). Mean flow and turbulence structure in vertical slot fishways, $J$. Hydraul. Eng., Vol. 132, No. 8, pp. 765-777.

[3] Rajaratnam N., Van der Vinne G., Katopodis C. (1986). Hydraulics of vertical slot fishways, $J$. Hydraul. Eng., Vol. 112, No. 10, pp. 909-927.

[4] Chow V.T. (1959). Open-Channel Hydraulics, McGraw-Hill Book Co., New York, p. 680.

[5] Fuentes-Pérez J.F., Sanz-Ronda F.J., de Azagra Paredes A.M., García-Vega A. (2014). Modeling water-depth distribution in vertical-slot fishways under uniform and nonuniform scenarios, J. Hydraul. Eng., Vol. 140, No. 10, pp. 2729-2737.

[6] Sun S.K., Deng Y.M., Li Y.Y. (2007). Hydraulic research on the layout of vertical slot fishway in Shangzhuang gate, Advancement of Hydraulics and Hydroinformatics, Nanjing: Hehai University Press, pp. 348-353.

[7] Xu T.B., Sun S.K. (2009). Numerical simulation of the flow structure in vertical slot fishway, J. Hydraul. Eng., Vol. 40, No. 11, pp. 1386-1391.

[8] Zhang G.Q., Sun S.K. (2012). Effect of slot width on the flow structure of vertical slot fishway, Journal of Hydroelectric Engineering, Vol. 31, No. 1, pp. 152156.

[9] Marriner B.A., Baki A.B.M., Zhu D.Z., Cooke S.J., Katopodis C. (2016). The hydraulics of a vertical slot fishway: a case study on the multi-species VianneyLegendre fishway in Quebec, Canada, Ecological Engineering, vol. 90, pp. 190-202.

[10] Caruso G., Cristofano L., Nobili M., Romano G.P. (2016). Experimental investigation on free surface vortices driven by tangential inlets, International Journal of Heat and Technology, Vol. 34, No. 4, pp. 653-662. DOI: 10.18280/ijht.340415

[11] Zhu Z.W., Li H.X. (2016). Experimental investigation on the anisotropic tensorial eddy viscosity model for turbulence flow, International Journal of Heat and Technology, Vol. 34, No. 2, pp. 186-190. DOI: $\underline{10.18280 / \text { ijht. } 340205}$ 